\title{
As Narrativas Pessoais no Processo de Ensino-Aprendizagem da Habilidade da Escrita em Espanhol
}

\author{
The Personal Narrative in the Process of Teaching-Learning \\ ABILITY OF Writing IN SPANISH
}

\section{Lúcia Kozow* Maria Inez Matoso Silveira**}

Resumo: A prática da escrita significativa no ensino-aprendizagem de língua estrangeira é sempre postergada e praticamente inexistente na educação básica. Neste trabalho, analisamos as estratégias narrativas utilizadas por uma aluna do ensino médio profissionalizante de uma escola pública, considerando a escrita e a reescrita de um texto produzido em espanhol. Este trabalho fez parte de uma experiência didática mais ampla posta em prática na última série do ensino médio, no Instituto Federal de Alagoas (IFAL), no campus Marechal Deodoro, no primeiro semestre de 2013, e teve por objetivo desenvolver a habilidade escrita dos alunos em Espanhol como língua estrangeira, numa visão de processo e na perspectiva de produção de um gênero textual. Para isso, utilizamos as narrativas pessoais, que são um gênero textual muito frequente nas nossas interações orais do dia a dia. Segundo Labov e Waletsky (1967), na estrutura interna dessas narrativas orais existem certos elementos que são geralmente incorporados pelas narrativas escritas.

\footnotetext{
* Doutora em Linguística pela Universidade Federal de Alagoas (UFAL). Professora do Instituto Federal de Alagoas (IFAL), campus Marechal Deodoro. Contato: luciakozow@yahoo.es.

** Doutora em Linguística pela Universidade Federal de Pernambuco (UFPE). Professora Associada do Centro de Educação da Universidade Federal de Alagoas (UFAL). Contato: mimatoso@uol.com.br.
} 
A análise mostrou que a aprendizagem da escrita aconteceu por meio de um processo, e que o uso do gênero narrativa pessoal como estratégia de ensino foi eficiente, na medida em que, supostamente, contribuiu para mostrar e ajudar a conscientizar a aluna colaboradora sobre como esse processo se realizou, a partir do ensino explícito que envolveu o planejamento, a escrita e a reescrita do texto produzido.

Palavras-chave: Narrativas pessoais. Ensino da escrita em espanhol. Ensino médio.

Abstract: The practice of significant writing in foreign language teaching and learning is always delayed and practically nonexistent in basic education. In this work we explore the narrative strategies used by a student of vocational secondary education at a public school, using the writing and rewriting of a text produced in Spanish. This work was part of a broader learning experience that was made in the last year of high school, at the Instituto Federal de Alagoas (IFAL), on campus Marechal Deodoro (MD), in the first half of 2013, and aimed to develop the writing skills of students in Spanish as a foreign language, under the view of a process and under the perspective of a production of a textual genre. For this, we used the personal narratives, which are a very common genre in our oral interactions of everyday life. According to Labov and Waletsky (1967), in the internal structure of these oral narratives, there are certain elements that are usually incorporated in the written narratives. The analysis showed that the learning of writing is a process, and that the use of the personal narrative genre as a teaching strategy was efficient to the extent that it helped to raise the student-participant's awareness about how this process took place, from the explicit teaching that involved the planning, the writing and the rewriting of the text produced.

Keywords: Personal narratives. Teaching of writing in Spanish. Secondary school. 


\section{Introdução}

A língua escrita, materna ou estrangeira, nas escolas de ensino médio, de maneira geral, sempre foi relegada a um segundo plano, e ainda hoje, como afirmou Geraldi (1997, p. 119) já há muitos anos, "confunde-se estudar a língua com estudar gramática”. Que a gramática é importante é um fato indiscutível; no entanto, privilegiar apenas o aprendizado da metalinguagem da língua, ou o aprendizado de exercícios estruturais de aplicação de noções e categorias é não valorizar o desenvolvimento das habilidades receptivas e produtivas da linguagem, como a lectoescritura.

Especificamente no que se refere ao ensino da escrita, Ann Raimes (1987) considera que essa habilidade pode ser praticada, no ensino de línguas, com vários propósitos, quais sejam: a escrita para reforço (para reforçar pontos gramaticais da língua); a escrita como treino (para treinar e combinar estruturas sintáticas); a escrita para imitação (para a aplicação e uso de fórmulas sociais e genéricas através de modelos fornecidos); escrita para comunicação (para exercitar a comunicação social); escrita para fluência (para desenvolver a habilidade da escrita e posterior edição); e finalmente a escrita para aprendizagem da língua (visão mais ampla da escrita que acumula os propósitos anteriores).

No presente artigo, apresentamos a análise da escrita e da reescrita de um texto produzido por uma das alunas participantes de uma pesquisa-ação ${ }^{1}$ realizada em duas fases denominadas como ensino implícito e ensino explícito. Nessa pesquisa tratamos, basicamente, de analisar o desenvolvimento da habilidade da escrita em espanhol como língua estrangeira, no ensino médio, numa visão de processo, centrada na produção

\footnotetext{
${ }^{1}$ A pesquisa foi realizada com alunos do ensino médio, do $4^{\circ}$ ano do curso Técnico Integrado em Guia de Turismo, na disciplina Língua Espanhola, no Instituto Federal de Alagoas (IFAL), campus Marechal Deodoro, durante o segundo semestre de 2013, e fez parte de um projeto de doutorado em Linguística Aplicada. Como procedimento didático básico foi proporcionado aos alunos uma fase de ensino implícito (imersão, por meio da leitura de vários gêneros narrativos, visando à familiarização com esses gêneros), e uma fase de ensino explícito (sistematização dos elementos da estrutura narrativa da narrativa pessoal e os recursos textuais-discursivos desse gênero).
} 
do gênero textual narrativa pessoal. A escolha da narrativa pessoal se deve ao fato de esse gênero ser uma prática muito frequente em nossas interações cotidianas. A produção escrita desse gênero, por parte dos alunos-colaboradores, possibilitou a observação e a análise da produção escrita dos estudantes, em sala de aula, realizando assim um continuum, da oralidade para a escrita, conforme preconizam os autores Marcuschi (2007) e Koch (2009).

A fundamentação teórica da pesquisa realizada baseou-se nos trabalhos dos sociolinguistas Labov e Waletsky $(1967)^{2}$. Com esses autores, surge o esboço dos elementos estruturais presentes nas narrativas, inicialmente nas orais e, posteriormente, nas narrativas escritas. Assim, essas partes, movimentos ou seções foram denominados como: resumo, orientação, complicação (da ação), resolução, avaliação, e a coda (fechamento). Nem sempre encontramos todos esses elementos ao mesmo tempo e seguindo essa mesma ordem nos textos. Contudo, ressalta Labov, que uma narrativa que apresenta todas as seções costuma estar bem elaborada.

Além disso, corroboramos Koch (2009, p. 36) com o fato de que "a escrita é um trabalho no qual o sujeito tem algo a dizer e o faz sempre em relação a um outro (o seu interlocutor/leitor) com um certo propósito". Consideramos, também, que a produção escrita de um texto acontece dentro de um processo: apontar ideias, fazer esquemas, redigir rascunhos, corrigir, revisar (CASSANY, 1993) dentre outros, e que essa produção envolve escolhas sintáticas, lexicais e retóricas (FLOWER; HAYES, 1981). Desse modo, reiteramos que o texto não deve ser visto apenas como um simples produto acabado, mas como resultado de um processo.

Desse modo, na análise que segue, mostramos, inicialmente, através da primeira versão da produção escrita da aluna-colaboradora, como se encontra constituída a estrutura linguístico-discursiva do texto. E, por meio da reescrita ${ }^{3}$, após o ensino explícito dos elementos da estrutura das narrativas

${ }^{2}$ Labov e Waletzky realizaram uma pesquisa sociolinguística entre os falantes do Black English utilizando como instrumento para coleta de dados as narrativas pessoais dos falantes colaboradores.

${ }^{3}$ A reescrita é vista como uma importante etapa da escrita, e vem sendo alvo de análises de vários autores brasileiros, dentre os quais: Jesus (2000), Geraldi (2001), Ruiz (2001), Serafine (2001), Antunes (2005), entre outros. 
conversacionais que aparecem nas narrativas escritas e a narração dos fatos em sequência lógica, mostramos também o uso dos tempos verbais no passado, os marcadores da temporalidade, e o uso de conectores que integram as frases, os quais são característicos do gênero textual narrativa pessoal. Por último, apresentamos um cotejo entre o texto escrito e o texto reescrito, no sentido de avaliar em que medida houve a utilização dos elementos da estrutura narrativa, explicitamente ensinados, bem como o uso de recursos discursivos próprios da narração.

\section{A Abordagem de Processo e os Modelos de Produção Escrita}

A abordagem do texto como um processo surgiu da necessidade de fazer com que o aluno entendesse o processo de criação do seu próprio texto e, assim, começasse a avançar na sua forma de produzir. Cassany (1997, p. 65), por exemplo, afirma que o aprendiz iniciante de uma língua, que necessita dominar as características do código, as quais se resumem em um extraordinário, vasto e variado conjunto de conhecimentos, para vir a tornar-se um escritor competente, pode encontrar todos os conhecimentos que necessita através dos textos já escritos por outros escritores.

Por exemplo, para se escrever uma carta, nada melhor que apropriar-se de outra já escrita. Cassany (1997, p. 65) considera que "somente em uma instância autêntica se pode encontrar a estrutura, o registro, e as palavras adequadas para escrever outra". Esta estratégia vale para todo e qualquer gênero textual que se necessite aprender, e não significa que haja uma dependência de um modelo para que se possa produzir um texto escrito, mas que, na prática, o uso de materiais autênticos favorece o processo de criação e produção do aprendiz.

Com o passar do tempo, os professores de línguas, que haviam recebido instrução a partir de métodos tradicionais, os quais consideravam o texto como produto final, que consistia numa produção coerente e sem erros, foram se dando conta que era preciso mudar e avançar. Desse modo, novas estratégias seguem sendo testadas. Entretanto, algumas resistências ainda persistem, já que a concepção do texto como um processo, na prática, traz consigo muitas exigências, e demanda conscientização e esforço, tanto dos aprendizes quanto dos professores de línguas. 
A escrita como processo também tem sido explicada através dos modelos cognitivos contemporâneos da escrita (ROHMAN, 1965; FLOWER; HAYES, 1981; VAN DIJK, 1983, 1988, dentre outros). Estes modelos se ocupam das operações mentais, as quais ocorrem nos processos de produção textual. Por certo, esse envolvimento de operações mentais é um dos motivos pelos quais se diz que escrever é um ato complexo (CASSANY, 1997, p. 64). Quando uma pessoa se determina a produzir um texto escrito, tem que buscar conteúdos, gerar novas ideias, decidir sobre como organizar o texto, pensar para quem será dirigido (audiência), ter clareza quanto aos objetivos, e manejar a linguagem de forma a conseguir o efeito desejado. E, nesse manejo da linguagem, terá que selecionar vocabulário, observar a pontuação, a ortografia, usar corretamente a sintaxe, tomar decisões sobre o estilo, prestar atenção na coerência e lógica do texto, dentre outras observações que vão permitir a produção de um texto considerado de boa qualidade.

Todas essas operações, como se pode ver, são de natureza complexa. A mente humana não consegue abordar todas as informações simultaneamente (IZQUIERDO, 2002). Nossa Memória de Curto Prazo (MCP) tem limitações, e nossa Memória de Longo Prazo (MLP) nem sempre nos permite acessá-la com facilidade. Os modelos cognitivos vieram contribuir, de maneira significativa, trazendo a compreensão de que a escrita necessita, entre outras coisas, de planejamento. No entanto, é preciso que se compreenda adequadamente o que isso significa, pois, na ação de planejar (GERALDI, 1997, p. 160; KOCH, 2009, p. 36, dentre outros), é preciso considerar o que se vai dizer (assunto/tema), como se vai dizer (conteúdo), para que (motivo) e a quem vai dirigido o que se escreveu (audiência).

Assim sendo, durante os últimos anos, as investigações sobre o processo de produção escrita têm orientado a elaboração de propostas didáticas para o ensino da escrita. Isso tem servido como suportes significativos para as práticas de ensino em sala de aula. Um modelo influente foi o de Flower e Hayes (1981), que tornou possível trazer para a escola uma concepção de escrita distinta da tradicional. A escrita de textos deixou de ser vista como um produto, passando a ser entendida como um processo. Nos anos posteriores, a proposta foi revisada, e também outras foram surgindo.

A proposta de Gordon Rohman (1965), uma das primeiras que surgiram, propõe dividir o processo de produção em três etapas: pré-escrever, 
escrever e reescrever. Pré-escrever engloba tudo o que acontece desde que o escritor pensa em escrever algo até que tenha uma ideia geral sobre o que vai escrever. Nela, há a elaboração do pensamento. Escrever e reescrever constituem as etapas de produção, propriamente ditas, e vai desde o momento em que se escrevem as primeiras ideias até que se corrija a última versão (modelo de etapas). Para o autor, a partir do que se descobre na pré-escrita será determinado o êxito da comunicação e produção escrita. O modelo desse autor veio a ser criticado, mais tarde, por Flower e Hayes (1981), por considerarem, entre outras razões, que o processo mental que a pessoa desenvolve ao elaborar o texto carece de melhor descrição.

Camps (1990, p. 3) considera que Rohman entende o processo de escrita como linear. Assim, o modelo de etapas se centra no processo de crescimento do texto como produto, sem levar em conta os processos internos do escritor. Para a autora, o processo não é linear, e essa opinião é compartilhada por muitos outros autores (CABRAL, 1994; DAHLET, 1994; DÍAZ; AYMERICH, 2003, entre outros), pois o escritor faz e refaz constantemente, (re)planeja, reescreve, corrige. E esses processos não seguem, dessa forma, uma série de etapas discretas, mas subprocessos que interagem uns com os outros. Essa é também uma consideração feita pelos autores Flower e Hayes (1981), e que os modelos cognitivos, de maneira geral, buscam explicar. Esta explicação se baseia no fato de que não são simplesmente etapas que se tem que seguir uma após a outra, mas operações que devem ser realizadas e que, com frequência, se aplicam recursivamente.

Um modelo também considerado importante foi o desenvolvido por Van Dijk (1983, p. 54-ss, 1988, p. 195-ss), estudioso da Linguística Textual (LT), que formula um modelo geral de processamento de textos, o qual inclui tanto a compreensão escrita quanto a produção escrita, de textos orais e escritos. Parte de alguns conceitos da LT (como: macroestrutura, coerência, regras, etc.), e segue um enfoque desenvolvido pela psicologia cognitiva. A preocupação reside nas operações mentais com as quais um indivíduo pode tratar os textos. Por exemplo, para compreender um texto, a pessoa pode utilizar-se de regras (operações mentais), extrair o sentido global, eliminar informações irrelevantes, entre outras. E para produzir um texto, pode desenvolver ideias gerais e abstratas, e buscar exemplos concretos de outros textos. 
O interessante desse modelo de Van Dijk é que mostra que as ideias que contem um texto não surgem do nada, geradas a partir de um ato criativo num momento de inspiração, mas que é, basicamente, o produto da reelaboração de informações antigas procedentes de outros textos. Nas palavras de Bakhtin (2011, p. 272), "cada enunciado é um elo na corrente complexamente organizada de outros enunciados", e podemos completar, de outros textos. Tudo isso não invalida o papel desempenhado pela criatividade na produção de um texto escrito. Afinal, a principal fonte de informação de quem escreve é o seu conhecimento de mundo, a sua memória, e os diferentes textos aos quais teve acesso.

Assim, um dos conceitos básicos da teoria de Van Dijk é o de macroestrutura, que é o conjunto das informações que o indivíduo elabora para processar um texto. Para elaborar e desenvolver as macroestruturas utiliza-se das macrorregras linguísticas (núcleo do modelo) de compreensão e de produção. Mais tarde, este modelo psicológico de elaboração do texto é reformulado em alguns pontos. Um deles é a substituição do conceito básico de regras para o de estratégias. Dessa forma, o autor se aproxima mais às colocações de Rohman e de Flower e Hayes, na medida em que há a compreensão de que o processo de produção escrita exige do produtor o uso de vários tipos de estratégias: ler, reler, fazer esquemas, rascunhos, correções, revisões, entre outros.

Entre as teorias e modelos, acima expostos, os autores Flower e Hayes (1981), ao interessar-se pelos processos cognitivos que intervém na produção de um texto, elaboram um modelo teórico mais detalhado, e que explica tanto as estratégias utilizadas para redigir (planejar, reler, revisar, fixar-se no conteúdo e depois na forma, etc.), quanto às operações intelectuais que conduzem a produção escrita, como a Memória de Curto Prazo (MCP), a Memória de Longo Prazo (MLP), objetivos, criatividade, etc. A teoria desses autores consta de três elementos essenciais, que se refletem nas três unidades do modelo, quais sejam: o ambiente de trabalho (task environment), que, além de dois elementos fundamentais - o problema retórico e o texto escrito inclui todos os elementos externos ao escritor: a audiência, o canal de comunicação, o propósito do emissor, dentre outros. Quanto à MLP, é onde o escritor armazena o conhecimento; e o terceiro elemento são os processos de escrita, especificamente os processos básicos de planejar, redigir e analisar, que são verificados mediante um controle (um monitor). 
Uma boa parte do processo de composição de um texto se processa no cérebro do escritor, é interno, não se pode observá-lo. Por isso, na visão da psicologia cognitiva, há o uso de entrevistas, de gravações, comparações de rascunhos, de produções, entre outros métodos que se fazem necessários, em consonância com os objetivos do pesquisador. Dois deles consistem, o primeiro numa análise introspectiva, e o segundo numa análise de protocolo (gravações), este usado por Flower e Hayes.

Assim, na análise introspectiva se pede aos escritores que escrevam um determinado texto e, depois de concluído, que expliquem tudo o que fizeram, desde o momento em que começaram a produção. Estes dados não são objetivos, pois dependem da visão de escrita que tenha o escritor. Já na análise de protocolo, os escritores verbalizam enquanto encontram-se produzindo, mas não analisam nem julgam o que escrevem. Este processo apresenta detalhes importantes que, provavelmente, não apareceriam em outro tipo de análise. Os autores Flower e Hayes consideram esse último processo como mais rico e objetivo. Em caso de pesquisa com alunos de ensino médio representa, também, em nossa opinião, uma forma eficaz e produtiva de coleta de dados, independente da estratégia protocolar utilizada.

A teoria do processo cognitivo elaborado por Flower e Hayes (1981, p. 365), encontra-se pautada em quatro pontos-chave:

1. O processo de escrita é mais bem entendido como um lugar de processos de pensamentos distintos que os produtores orquestram ou organizam durante o ato de produção;

2. Esses processos têm uma hierarquia, altamente embutida na organização em que algum processo dado pode ser embutido no interior de algum outro;

3. A ação de produção, em si mesma, é um processo de pensamento orientado a uma finalidade, conduzido por uma rede de objetivos cada vez maiores, e próprios do produtor;

4. Produtores criam seus próprios fins de duas maneiras: propondo objetivos de alto nível, e respaldando objetivos subordinados que dão vida ao sentido de propósito que se vai desenvolvendo no produtor, e, então, às vezes, mudando os principais objetivos ou ainda estabelecendo outros totalmente novos, com base no que se aprendeu através da produção propriamente dita. 
A partir da exposição desses quatro pontos-chave, percebe-se que o primeiro engendra todos os demais. Entretanto, apesar de ser um sistema hierárquico, as unidades não atuam em uma ordem rígida como no modelo de etapas de Rohman (pré-escrita, escrita e reescrita). Os processos podem ser encadeados uns aos outros, pois o ato da escrita envolve pensamento, e, portanto, pode-se mudar a qualquer momento. Isso implica dizer que, na produção de um texto, começamos com uma ideia, mas depois geramos outras, (re)planejamos tudo e, desse modo, se incluem novos processos: organizar, redatar, revisar, avaliar. Esses processos de pensamento são denominados por Flower e Hayes (1981) como ferramentas que os autores utilizam para construir o texto.

Por certo, a construção de um texto é também organizada pelo escritor por meio de uma complexa rede de objetivos (globais e locais), os quais se relacionam entre si. Esses objetivos também possuem uma estrutura hierárquica, de maneira que um objetivo local desenvolve alguma função dentro de um objetivo global, e este vai proporcionar a coerência no texto. Essas redes de objetivos não se criam em uma determinada fase ou etapa, como a da pré-escrita, por exemplo, mas durante todo o processo de elaboração do texto, à medida que vai evoluindo. Flower e Hayes (1981) dizem que os conhecimentos que temos a respeito do funcionamento dessas redes são muito limitados.

Além dessas redes de objetivos, o processo de construção de um texto é entendido como aquele que se dá por meio de uma série de decisões tomadas pelo produtor durante a elaboração até chegar à versão final do escrito. Essas decisões dependem da escolha do tema/assunto, do gênero textual escolhido, e a quem será dirigido (audiência). Todas essas questões envolvem uma questão maior, que é o propósito da escrita, a sua finalidade e, consequentemente, afeta os critérios, os quais vão regular as decisões do produtor. Para Flower e Hayes (1981), é no ato de produzir que o produtor volta a gerar ou recriar seus próprios objetivos à luz do que aprendeu.

Assim sendo, é durante todo o processo de construção que se produz a ação da aprendizagem. O produtor irá utilizar aquilo que aprendeu para gerar os objetivos e a elaboração do texto. Flower e Hayes (1981) sustentam que as ações de aprendizagem podem ser analisadas por meio da observação de como o produtor planeja o texto, e como vai gerando os objetivos que 
serão necessários à construção desse texto. Os autores sugerem que a criatividade e a invenção do produtor estão estreitamente relacionadas com essas ações.

Isso tudo nos leva a perceber, como já havíamos mencionado no começo desse tópico, que as situações autênticas de produção textual são de singular importância, pois elas fazem parte da realidade psicossocial dos alunos e, desse modo, estão presentes na sua conduta linguística. Para que a produção textual se realize é importante que o produtor, nesse caso o aluno, tenha o que dizer, e que esteja motivado a produzir. Nas palavras de Leal (2004, p. 41), "a produção textual requer processos ligados à geração do conteúdo (produção de idéias) e à textualização (organização das idéias em produto lingüístico). No caso do texto escrito, somam-se os processos de registro do texto e atendimento às normas da língua". Afinal, considerar o texto como processo implica a revisão de um complexo processo linguístico e cognitivo, que se põe em marcha a partir do momento em que se planeja e se concretiza a escrita de um texto.

Nesta perspectiva, o estudo voltado para o uso dos gêneros textuais no ensino da escrita de uma língua permite a aquisição de habilidades linguísticas, as quais podem ser usadas a favor do propósito discursivo. Serafini (2001, p. 22) expressa a convicção de que "é possível ensinar a compor porque é possível dividir o processo da composição em atividades básicas e utilizar, para cada uma delas, técnicas e procedimentos específicos”. Assim, o uso dos diferentes gêneros textuais no ensino de uma língua estrangeira na prática de sala de aula favorecerá aos estudantes a apropriação dos vários aspectos constitutivos dos distintos textos. Esta apropriação propiciará, também, aos discentes, usar os gêneros textuais como exemplos nas mais diversas esferas de atuação humana.

Silveira (2006) corrobora esta afirmação, no tocante as narrativas pessoais como um gênero textual, ao considerar que "as narrativas, como uma atividade de alta freqüência nas práticas sociais, podem incrementar tanto as atividades orais como as escritas em sala de aula em todas as séries do ensino fundamental e médio", além de promover ou contribuir com o desenvolvimento consciente da habilidade da escrita no idioma estudado. 


\section{A Produção Escrita da Aluna-Colaboradora}

Convém lembrar que a análise aqui relatada foi recortada de uma pesquisa-ação mais ampla que envolveu a produção escrita da narrativa pessoal num contexto de sala de aula, em que os alunos discutiam, em duplas, como iriam escrever o texto. Era permitido fazer qualquer tipo de pergunta, tanto à professora-pesquisadora quanto a outro aluno da sala. Concluída e entregue a produção escrita, de forma individual, foi dado, na aula seguinte, um feedback aos alunos. Nele, a professora-pesquisadora fez uma correção classificatória (RUIZ, 2001; SERAFINI, 2001), por meio de símbolos (tabela de conversão acordada com os estudantes com antecedência), indicando os problemas encontrados nos textos, e solicitou a sua reescrita.

Assim, nesta seção, apresentamos a análise da escrita e da reescrita de um desses textos, o qual foi produzido por uma das alunas participantes da experiência de ensino já mencionada. Na produção escrita (Figura 1), vamos mostrar como se encontra organizada a estrutura linguístico-discursiva; na produção reescrita (Figura 2), analisamos a microestrutura à luz da fundamentação teórica adotada; e, a seguir, fazemos um cotejo entre a escrita e a reescrita. Na realização deste cotejo, analisamos, inicialmente, se houve alguma mudança de ordem estrutural ou discursiva entre a primeira e a segunda versão escrita do texto.

\section{A estrutura linguistico- discursiva presente na escrita}

O texto apresentado (Figura 1, a seguir) foi produzido após o término da instrução explícita sobre o gênero textual narrativa pessoal, os elementos de sua estrutura e seus recursos textual-discursivos. O texto da alunacolaboradora, apesar de apresentar alguns deslizes no conhecimento sistêmico da língua, permite-nos afirmar que existe uma aproximação, desde o início, da estrutura prototípica do gênero narrativa pessoal, tais como o uso da narração em primeira pessoa, elementos narrativos, tempos verbais adequados, principalmente o passado, dentre outros recursos próprios da narrativa. 


\begin{abstract}
Durante años, siempre me despierto al mismo tiempo, hago las mismas cosas y me siento feliz por eso. Pero un dia sucedió algo diferente que se metió com mi rotina e fue bastante divertido.

Mi rotina también se mantiene en los fines de semana. El domingo yo acuerdo más temprano para prepararme para mis atividades. Aunque mi organismo esteja acostumbrado a ella, siempre pongo el alarme del teléfono para no arriesgar a perder el tiempo.

En el sabado por la noche, antes de dormir, poní el alarme por el dia siguiente y en el domingo me desperté con el ruido de el mismo. Me duché, me preparé y salí de mi casa para ir a La Missa. La calle estaba desierta, ni coche, ni personas. Me pareció raro, pero yo continué mi camino.

Al llegar a la Iglesia sólo tenía duas personas e el señor de la puerta. Luego se descobrió que raro, puesto que ya estaba cerca el momento de empezar la Misa y nadie había llegado. Me fui a mi lugar, pero yo estaba inquieta. Me levanté y fui hablar con el señor de la puerta. Pregunté se no había cambiado la hora de la Missa y él me respondió que no. No tenía empezado aunque puesto que era muy temprano. ¿Temprano? Yo no entendi. Él me dijo que si, aún eran las 5:45h. Miré el tiempo en el teléfono y era $6: 45 \mathrm{~h}$. Fue saboteada por el horario de verano que se había empezado en la noche y el teléfono se atualizó automaticamente. Entendi todo.

Entonces esperé casi una hora para la Missa. Fue bueno que y oré mucho más. Me dia fue estupendo, mismo con ese contratiempo.
\end{abstract}

Fonte: Dados de pesquisa - narrativa pessoal

Figura 1 - Escrita do texto da aluna Pilar ${ }^{4}$

O início da produção escrita (Figura 1) leva o leitor a pensar que se trata apenas de uma descrição de atividades do cotidiano. No entanto, configura-se como uma estratégia que a aluna/autora usa para afirmar que tem uma rotina que a acompanha desde há muitos anos, e que se sente feliz assim. Para Koch (2009, p. 36), o como dizer aquilo que se quer dizer é revelador de que a escrita é um processo, e que envolve a escolha de um gênero textual para que, por meio dele, a comunicação se realize. A partir da primeira afirmativa a respeito da sua rotina, a aluna/autora começa a introduzir os fatos que aparecem quando essa mesma rotina é interrompida por meio do surgimento de algo novo (é uma ação que se encaminha para uma complicação e, finalmente, para um clímax). Assim, aos poucos, a produção de Pilar começa a ser configurada como uma narrativa pessoal. Para Álvarez (2003, p. 31), “a narração em $1^{\text {a }}$ pessoa tem a vantagem de aumentar o interesse sobre o que é narrado, pois dá a aparência de algo vivido e experimentado pessoalmente, com mais autenticidade do que se fosse empregado na $3^{\text {a }}$ pessoa". Por certo, percebe-se que o primeiro

${ }^{4}$ Nome fictício, para melhor preservar a identificação da aluna-colaboradora. O texto se encontra transcrito de maneira fiel à forma como foi produzido. 
parágrafo do texto da Figura 1 anuncia um acontecimento, o qual se dá num momento passado, e é exatamente por isso que há uma quebra ou uma espécie de interrupção de sentido no que se estava dizendo, quando se volta, abruptamente, para um tempo presente - mi rutina también se mantiene en los fines de semana (linha 3) -, no parágrafo seguinte.

Ainda no segundo parágrafo, apesar de haver exposto o que aconteceu no domingo, Pilar começa a relatar o que fez no sábado, invertendo a ordem corrente dos dias da semana. Existe uma espécie de movimento que vai e vem, numa tentativa de fechar um resumo inicial. Uma espécie de anúncio da narrativa propriamente dita, a qual viria realmente a acontecer a partir do início do terceiro parágrafo (linha 6), com o final de semana começando no sábado.

A partir de el sábado por la noche (linha 6) começa uma sequência de novas ações utilizadas para introduzir a história narrada. Adam (2008, p. 224) afirma que "uma narrativa que é constituída somente por uma simples enumeração de uma seqüência de ações e/ou eventos possui um baixo grau de narrativização". Contudo, nesse texto, a história contempla, além das ações e eventos, um acontecimento inesperado, o qual envolve sentimentos (especialmente a religiosidade - ir à missa), um pouco da subjetividade, as situações de interação e o posicionamento da aluna-colaboradora em relação aos fatos narrados, os quais deixam entrever a intrínseca relação entre linguagem, mundo e práticas sociais.

No tocante aos tempos verbais do passado, próprios da narrativa, Pilar consegue utilizá-los bem, apesar de alguns deslizes ortográficos, mas que não comprometem o conteúdo semântico-discursivo. Consegue fazer um encadeamento das ações, permitindo, assim, que o texto progrida. Faz, também, uma breve descrição do lugar - la calle estaba desierta, ni coche, ni personas (linha 8) - e, em seguida, emite uma opinião - me pareció raro -, ou seja, faz uma avaliação, chamando a atenção do leitor para os fatos que virão a ser narrados a seguir.

O quarto parágrafo mostra, efetivamente, o começo da complicação. Participam da história, como personagens, a narradora, duas pessoas, as quais estavam na igreja, e um senhor que se colocava à porta. $\mathrm{O}$ assunto gira em torno de uma confusão relacionada ao esquecimento do horário de verão. A personagem/narradora chega à igreja com uma hora de antecedência 
e aí começa a complicação. Somente se dá conta do ocorrido quando fala com o senhor que se encontra à porta. A situação é esclarecida, ou seja, ocorre a resolução, e a narradora encerra a sua narrativa com um final feliz.

\section{Os elementos narrativos e a estrutura sintática presentes na reescrita}

$\mathrm{Na}$ análise da reescrita (Figura 2, a seguir), procuramos investigar a presença e o uso dos elementos que formam a estrutura de uma narrativa. Além disso, na narração se contam os fatos ocorridos ao longo do tempo de tal modo que, ao se encadearem uns com os outros, acabam adquirindo um novo significado. Como se trata de mostrar ações, de comunicar fatos sucedidos, há o emprego de verbos no tempo adequado (passado) que são característicos da narração.

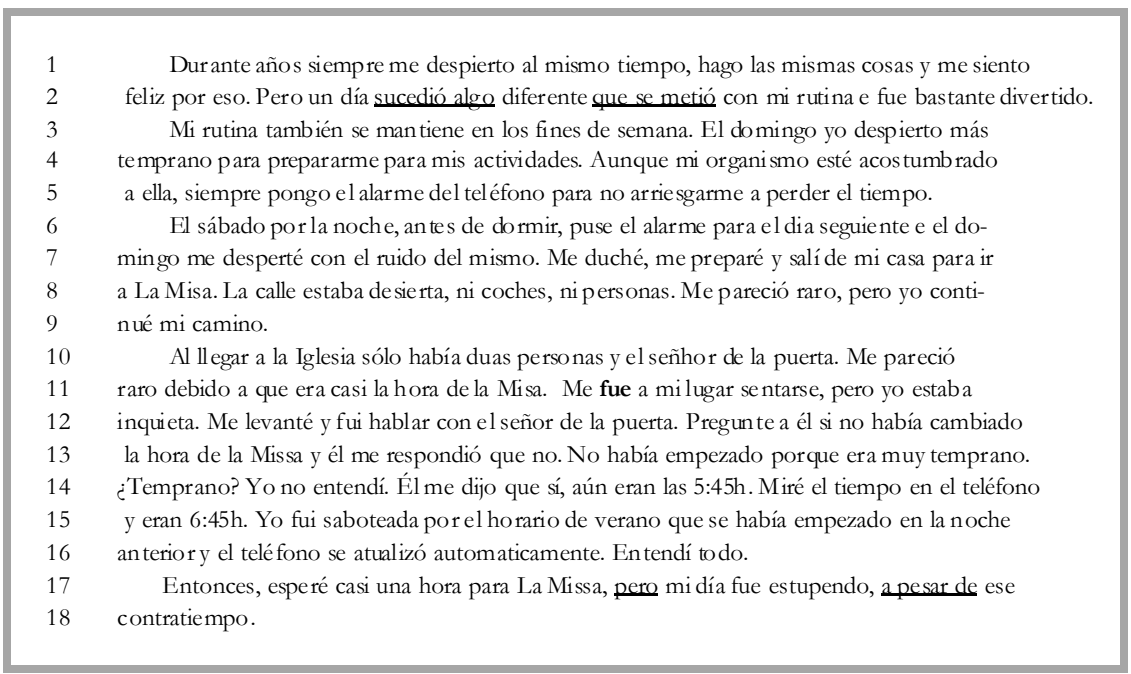

Fonte: Dados de pesquisa - narrativa pessoal

Figura 2 - Reescrita do texto da aluna Pilar

No que concerne à estrutura narrativa, podemos notar que Pilar tentou utilizar os elementos constituintes da estrutura da narrativa. Pode-se perceber que inicia o texto tentando organizar, e oferecer ao leitor um resumo daquilo 
que vai expressar em seguida, por meio da escrita. A intenção é mais tentar despertar o interesse do leitor do que resumir a narrativa. Isso retrata claramente as duas funções que o resumo pode ter: função referencial e função fática (BASTOS, 2001, p. 84).

Ainda no primeiro parágrafo da Figura 2, vemos uma tentativa de chamar a atenção do leitor para o fato que vai ser contado, de criar certo clima, quando diz que sucedió algo e esse algo, se metió (linha 2 - sublinhado) com sua rotina. Nesse momento, o leitor cria uma expectativa a respeito do que pode vir em seguida, o que denominamos como clímax. Também é visível o uso da orientação, a qual situa o leitor por meio da expressão de tempo - durante años (linha 1) -, de lugar (implícito - a residência e depois a igreja), de pessoa (o uso dos verbos em primeira pessoa, tornando a autora/protagonista identificada), e cumpre, dessa forma, uma função referencial (BASTOS, 2001, p. 26). Contudo, pode-se observar que o resumo e a orientação encontram-se de certa maneira mesclados. Segundo Labov (1972), essa ocorrência costuma ser comum nas narrativas.

A história começa, de fato, a ser contada a partir do terceiro parágrafo, que é quando a autora fala dos afazeres do sábado. Ocorre uma pequena heterogeneidade tipológica (MARCUSCHI, 2010, p. 33), passando da narração para uma descrição, em que as ações são descritas, desde que a personagem (a aluna/autora) se levantou no domingo, até o instante em que saiu de casa para ir à missa. Essa descrição se estende para o que acontece no exterior da casa, já na rua. Neste ponto, observa-se uma tentativa de instigar certo ar de mistério à narração quando Pilar diz: me pareció raro, pero yo continué mi camino (linhas 8 e 9 - sublinhado), fazendo uma avaliação.

Van Dijk (1983, p. 154), nesse sentido, diz que "a primeira característica fundamental do texto narrativo consiste em que este texto se refere antes de tudo a ações de pessoas, de maneira que as descrições de circunstâncias, objetos ou outros acontecimentos ficam claramente subordinados". Essas ações, às quais se refere o autor, são colocadas explicitamente por Pilar no texto. Corroborando as palavras de Van Dijk, Álvarez (2003, p. 22) acrescenta que "os textos narrativos são mistos, pois incluem a descrição e o diálogo, como formas expressivas imprescindíveis". Essa autora considera que ambos representam o meio adequado para caracterizar personagens (descrição e diálogo) e ambientes (descrição). 
No quarto parágrafo, observa-se que a palavra igreja está escrita com inicial maiúscula - Iglesia (linha 10) -, e também a palavra missa (em português) grafada em espanhol - Misa (linha 11). Esta aparece, assim, em várias ocasiões no decorrer do texto. Essa forma de escrita não é feita de maneira aleatória. Nela está demonstrada, além dos sentimentos, também, a religiosidade de Pilar.

Além do aspecto acima apontado, ao começar a contar o que havia sucedido, aparece expressa uma opinião - me pareció raro (linha 10) - e, mais adiante, outra que também demonstra um sentimento, por meio de uma pergunta em formato de indagação a si mesma - ¿temprano? (linha 14) -, demonstrando não estar entendendo o que estava acontecendo. Segundo Dionísio (1994, p. 13), numa perspectiva linguístico-pragmática, comentários, reflexões, hesitações expressas entremeando a narração são de fundamental importância. Essas formas de expressão mencionadas constituem, na narrativa, uma parte importante chamada de avaliação. Quando encontramos, no texto, formas de avaliação, o conteúdo da escrita se torna mais interessante. No entanto, não há regras para produzir o interesse do leitor. Para Labov e Waletzky (1967), os comentários avaliativos são geralmente distribuídos ao longo de toda a narrativa, e são considerados como uma estrutura secundária.

Com efeito, Van Dijk (1996, p. 62) considera que "na narração linear dos fatos, o narrador pode inserir percepções, interpretações ou avaliações específicas para explicar o que se passou". No texto em estudo, principalmente, devido à história ser narrada em primeira pessoa, Pilar externaliza, por meio de comentários avaliativos, formas de sentimentos (inquietação), e de interpretações (troca de horário) dadas aos acontecimentos narrados. Entretanto, esses comentários avaliativos, acima abordados, diferenciam-se da avaliação, propriamente dita, quando esta indica a razão de ser da narrativa, o porquê de ter sido contada a história, e onde o narrador estava querendo chegar. Esta avaliação mais efetiva não aparece, contudo, no texto em tela.

Convém salientar que, assim como no terceiro parágrafo, no quarto também ocorre uma descrição de uma sequência de ações e, através dela, observa-se o uso dos tempos verbais do passado, característicos da narrativa. Esses verbos definem uma sequência de ações: me pareció, me fui, me levanté, pregunté, no entendí, miré, fui, esperé. Nessa sequência, os acontecimentos formam 
a ação de complicação. Segundo Schiffrin (1981, p. 49), "a ação de complicação é a parte que conta a história, veiculando uma série de acontecimentos narrativos ordenados temporalmente". O objetivo é adicionar informações para que o leitor possa compreender ou interpretar os acontecimentos narrados.

Para Álvarez (2003, p. 18), “o específico da narração é o princípio da ação. Escrever os fatos ocorridos ao longo de um tempo e espaço é uma tarefa bem complexa". A autora diz que isso se deve à maneira sobre como os acontecimentos se encadeiam entre si; fazendo com que aquilo que se narra adquira um significado. Nisso se encontra a ideia de processo, desde que a história começa até que adquira um término lógico.

Além do pretérito perfecto simple ou indefinido usado no encadeamento das ações, conforme mencionado anteriormente, outro tempo verbal que, por vezes, costuma aparecer nas narrativas, ainda que em menor frequência, porém não menos importante, é o pretérito imperfecto, que é o tempo verbal adequado das descrições (BASSOLS; TORRENT, 1997, p. 184; ÁLVAREZ, 2003, p. 34, dentre outros). Este tempo verbal se encontra representado no texto de Pilar, basicamente, pelos verbos ser, estar e haver. São eles: era(n) (linhas 11, 13, 14 e 15), estaba (linhas 8 e 11) e habia (linha 10). Na narrativa, o uso do imperfecto remete a uma ação mais longínqua no passado, quando comparado ao pretérito perfecto simple.

Além do imperfecto, ocorre também, logo no início do texto, a presença de verbos no presente - me despierto, me siento, se mantiene, pongo (linhas 1, 3 e 5). Em algumas ocasiões, se usa esse tempo verbal "com a intenção de acercar o passado ao presente do leitor, ou seja, de atualizar os fatos relatados, ao mesmo tempo em que inclui certo tom evocador" (ÁLVAREZ, 2003, p. 34). Isso se observa quando Pilar começa evocando ou se referindo ao passado - durante años (linha 1) -, usando o presente.

Além dos tempos verbais característicos dos diversos gêneros textuais da narrativa, e também da narrativa pessoal, os conectores discursivos são outros aspectos linguísticos a serem observados no texto da Figura 2. A presença de um número acentuado dessas unidades linguísticas na produção escrita significa que a autora deseja explicitar as relações lógicas existentes entre as ideias expressas por meio das orações que, juntamente com a progressão temática, vão guiar o leitor até chegar ao final do texto. Por 
outro lado, se existem poucos conectores, não significa, necessariamente, que o texto esteja mal ou pouco elaborado; isso representa uma estratégia do produtor que envolve a interação escritor-leitor, no sentido de fazer com que o leitor seja ativo e participativo, e que construa as relações entre os enunciados.

Desse modo, dispomos de um grande número do mesmo conector aditivo y (linhas 1, 2, 6, 10, 12, 13, 15 e 16). Os conectores aditivos demonstram a construção das orações coordenadas. A função deles é incluir informações novas ou reforçar o que se disse anteriormente. Percebe-se que o uso abarca, basicamente, a primeira função. Já na linha 2, aparece iniciando o período outro conector, o contra-argumentativo pero antecedendo uma expressão temporal. A impressão que se tem é que, nesse momento, vai se iniciar a narração da história. No entanto, esse início é postergado. Esse mesmo conector volta a aparecer no terceiro e quarto parágrafos (linhas 8 e 11), e no encerramento do tex to (linha 17), seguido por outro a pesar de, representando esses conectores, o mesmo valor contrastivo.

$\mathrm{O}$ uso de aunque (linha 4), ainda que possa estar empregado corretamente, segundo Milani (2000, p. 187), "o verbo da oração subordinada aparecerá no subjuntivo quando o falante não tiver prévio conhecimento ou vivência da situação mencionada, ou ainda não lhe interessar demonstrar ou assumir essa falta de conhecimento ou vivência”. Esse não parece ser o caso de Pilar, pois demonstra pleno conhecimento daquilo que expressa. Outros conectores aparecem marcando algumas orações subordinadas; um exemplo deles é o porque (linha 13), que foi usado adequadamente, com valor ao mesmo tempo explicativo e causal, o qual representa a explicação e o motivo de não haver começado a missa.

Outro exemplo do uso dos conectores encontra-se no início do encerramento do texto. Trata-se do conector continuativo entonces (linha 17). Sua função é continuar com o mesmo tema, servindo como argumentador da coesão lógica, e mostrando, assim, a organização discursiva. Trata-se do conector consecutivo menos gramaticalizado (PORTOLÉS, 1998, p. 140) e aparece, tanto na escrita quanto na reescrita, introduzindo o estado final ou a resolução de toda a história narrada. A posição de iniciador do parágrafo fica um pouco estranha, já que é um continuador. A narrativa poderia ter sido encerrada com a frase entendí todo (linha 16) sem prejuízo para a 
compreensão semântica. No entanto, Pilar faz a opção por dar mais informações a respeito de suas ações finais, com o objetivo de concluir em definitivo a história, e nisso deixa evidente a sua subjetividade.

\section{O cotejo entre a escrita e a reescrita}

A produção textual de Pilar apresenta alguns deslizes ortográficos, e algumas interferências interlinguísticas. Muitos autores (CASSANY, 1993; CABRAL, 1994; REYES, 2006, dentre outros) chamam a atenção para o fato de que não se deve priorizar como tem sido uma prática frequente nas escolas, apenas os aspectos formais da produção linguística dos alunos, como os problemas ortográficos, por exemplo. De fato, a partir desses aspectos formais, costuma-se promover uma reescrita, como ressaltam Schneuwly e Dolz (2004, p. 99) e Jesus (2000, p. 101), fazendo apenas "uma higienização do texto do aluno", sem se dar a devida importância às relações de sentido emergentes na interlocução.

A produção escrita de Pilar, dentro de uma perspectiva geral, permitenos afirmar que apresenta características que a denominam como uma narrativa pessoal. Pilar começa o texto com uma expressão temporal durante años, a qual, por si só, é um indício de que vai começar a contar ou narrar uma história.

No primeiro parágrafo, encontramos uma interferência da Língua Materna (LM) no uso do conector aditivo y (linha 2), o qual é substituído pelo aditivo 'e' do português, e que segue igual na reescrita. Contudo, esse uso não apresenta nenhum prejuízo ao conteúdo semântico-discursivo. Koch (2009, p. 37) também ressalta a importância de se ter o conhecimento da ortografia, da gramática e do léxico da língua. Para a autora, esses conhecimentos ajudam o escritor a ter uma atitude colaborativa no sentido de evitar problemas de comunicação, além de se dispensar atenção e consideração ao leitor.

No segundo parágrafo, Pilar fala sobre as atividades realizadas no domingo. Na escrita da Figura 1, usa um falso cognato da língua portuguesa, o verbo acordar (linha 3). Não se dá conta, inicialmente, de que não está expressando o que deseja, já que, em espanhol, o vocábulo possui um significado totalmente distinto. Contudo, esse problema é parcialmente 
resolvido, na reescrita, com a substituição do verbo acordar (português) pelo verbo reflexivo em espanhol despertarse, apesar do deslize da ausência do pronome me referente à primeira pessoa. Percebe-se que há uma dificuldade no manejo dos verbos reflexivos, pois, logo em seguida, aparece a dúvida arriesgar/arriesgarse. O primeiro é usado na escrita (Figura 1 - linha 5) e substituído pelo outro na reescrita (Figura 2 - linha 5). Outro exemplo é o verbo sentarse (linha 11), o qual aparece somente na reescrita.

Ainda no âmbito linguístico, observamos que a influência da LM é outro aspecto presente na produção escrita em espanhol, principalmente devido à enorme semelhança no léxico das duas línguas, acarretando o que se costuma chamar de interlíngua. Isso, às vezes, traz consequências negativas, porque o aluno não consegue separar o que pertence a um ou a outro idioma. Como exemplo disso, o uso de el alarme $^{5}$ para o correspondente em português o alarme. Efetivamente, as questões de gênero são consideradas normalmente problemáticas, especialmente para o aluno principiante. O apelo à LM provoca, segundo Bechara e Moure (2002, p. 9), "um estancamento no plano de desempenho do estudante", já que a semelhança existente conduz, muitas vezes, a transferências inadequadas no plano lexical, gramatical e, também, no fonológico. Isso acaba prejudicando a comunicação e, na maioria das vezes, comprometendo a produção escrita na língua espanhola.

O terceiro parágrafo da reescrita inicia com uma correção entre o uso de artigo acompanhado ou não de preposição en el/el (linha 6) antes dos dias da semana. Esta é uma dúvida própria dos principiantes, mas que, às vezes, acompanha o aluno por muito tempo durante a aprendizagem do espanhol. É interessante observar que, na reescrita, Pilar se dá conta de alguns equívocos relacionados à ortografia, passando, por exemplo, a usar o artigo adequado, como no caso mencionado acima, e revisa a grafia do verbo poner (linha 6). Contudo, percebe-se que as revisões realizadas, até esse ponto, se dão apenas no âmbito linguístico. Não há mudanças relacionadas ao conteúdo discursivo. Isso indica que caberia maior reflexão, no sentido de melhorar a organização estrutural do resumo e da orientação, por exemplo, que, em determinado

${ }^{5}$ Como se sabe, a palavra alarme, em espanhol, é feminina (alarma); e como inicia por uma vogal tônica, de acordo com a regra gramatical, deve vir antecedida pelo artigo definido no masculino (el alarma). 
momento, parecem entrecruzar-se, fazendo com que o leitor tenha que se movimentar, retroagindo no texto, e não seguindo adiante, tornando a progressão mais lenta.

Outro exemplo de reestruturação relacionado ao âmbito linguístico é observado no quarto parágrafo. Pilar inicia eliminando a interferência da LM tener/haber (linha 10 - sublinhado) que aparece, novamente, mais abaixo (linha 13 - sublinhado). Esses dois usos são resolvidos na reescrita. Em sentido contrário, ainda nesse parágrafo, Pilar promove uma reestruturação importante relacionada à coerência do texto. $\mathrm{Na}$ escrita usa o conector consecutivo luego (linha 9) e o conector causal puesto que (linha 10), e os elimina na reescrita. Essa eliminação não se dá de forma aleatória, implica uma reflexão. Vejamos os seguintes exemplos (1) e (2):

(1) Luego se descubrió que raro, puesto que ya estaba cerca el momento de empezar la Misa y nadie había llegado (escrita).

(2) Me pareció raro debido a que era casi la hora de la Misa (reescrita).

No exemplo (1), o conector luego iniciando o período não justifica o lugar ocupado, pois não indica um efeito, um resultado ou uma consequência da ação expressa pela oração principal. Assim sendo, a sua eliminação na reescrita foi adequada. Quanto ao uso do segundo conector puesto que, devido à má estruturação da oração que o antecede, acaba, também, resultando inadequado, e, assim, sua eliminação na reescrita não ocasionou nenhum problema. O exemplo (2) mostra uma estrutura mais adequada ao uso da língua espanhola. A presença do conector causal (sublinhado) mostra a razão da ação expressa pelo verbo da oração principal. Assim, entre os dois exemplos, podemos afirmar que na reescrita ocorreu um avanço significativo na produção da escrita do texto, principalmente no que se refere ao conteúdo linguístico-discursivo. Outro exemplo semelhante ocorreu mais adiante, com as seguintes estruturas:

(3) No tenía empezado aunque puesto que era muy temprano (escrita).

(4) No había empezado porque era muy temprano (reescrita). 
O exemplo (3) inicia com o emprego equivocado do verbo tener em substituição ao auxiliar haber. E o mais interessante: o uso de dois conectores juntos aunque e puesto que. Por mais que o uso esteja inadequado, isso é muito significativo, porque mostra o interesse da aluna em utilizar os conectores discursivos, na tentativa de produzir um bom texto. O exemplo (4) vem a demonstrar que conseguiu resolver tanto a questão do uso adequado do auxiliar, quanto o emprego do conector, tornando a estrutura aceitável na língua espanhola.

Quanto aos aspectos semântico-discursivos, de maneira geral, Pilar consegue transmitir fatos e ideias. $\mathrm{Na}$ escrita, algumas formas de expressão confundiriam o leitor de fala espanhola, como yo (me) acuerdo más temprano (linha 3); no entanto, para o leitor brasileiro, o texto como um todo é de fácil compreensão e interpretação. A autora fala do seu equívoco quanto à mudança de horário, devido ao horário de verão; mostra que é uma pessoa religiosa, é católica, vai à igreja e frequenta a missa. Ao encerrar o texto, Pilar faz uma nova tentativa pelo uso dos conectores, e usa pero e a pesar de (linha 17 sublinhados), na reescrita. Com isso, consegue deixar a estrutura mais bem elaborada e mais aceitável na língua espanhola. Ressalte-se que o uso dos conectores em espanhol, normalmente, apresenta um grau elevado de dificuldade para os estudantes em geral. Fica, dessa maneira, comprovado que o processo de reescrita, compreendido não como uma simples reprodução do mesmo texto, implica, antes de tudo, uma atividade reflexiva, pois é permeado por hesitações, elaborações e reelaborações. Isso conduz a uma atividade de controle do próprio texto, efetivado pelo aluno que o produziu.

\section{Considerações Finais}

A habilidade de aprender a escrever numa língua estrangeira é uma das tarefas mais difíceis que o estudante tem que enfrentar, principalmente quando se trata de um principiante, apesar de o brasileiro não ser propriamente assim considerado quando se trata do processo de ensino-aprendizagem do espanhol. Contudo, precisa vencer muitos obstáculos, pelo fato de não possuir internalizadas as estruturas do novo idioma. 
A análise da produção escrita efetivada pela observação das duas fases, a escrita e a reescrita, possibilitou algumas descobertas importantes relacionadas ao processo de ensino-aprendizagem da habilidade escrita em língua espanhola. Uma delas, por exemplo, evidencia que o gênero textual empregado, a narrativa pessoal, foi eficaz como elemento motivador para o desenvolvimento da habilidade da escrita e que, por meio da reescrita, o aluno pode visualizar com mais propriedade o resultado do que produziu, e, principalmente, daquilo que aprendeu. Embora se tenha constatado que a reescrita nem sempre contempla todas as correções que se fazem necessárias, ocorrendo, dessa forma, equívocos de correção.

Ainda no tocante ao processo de ensino-aprendizagem da habilidade da escrita em língua espanhola, verificou-se que o uso da estrutura das narrativas pessoais e de seus elementos constitutivos mostrou-se eficiente para dar um feedback à aluna-colaboradora a respeito das habilidades de produção textual e de uso da língua, apesar das limitações encontradas no conhecimento do idioma. É interessante ressaltar, também, a importância de se trabalhar a escrita na visão de que as ações, relacionadas ao ato de escrever, devem acontecer dentro de um processo, e este não é linear, mas recursivo, pois envolve planejar, pensar, ver, rever, revisar e, depois de finalizado o texto, muitas vezes achar que ainda devem-se efetuar novas modificações. Finalmente, deve-se compreender que escrever aprende-se na interação contínua com os atos de escrita, através de estratégias significativas, em que o aprendiz poderá entender o caráter dialógico da linguagem, e refletir sobre seu próprio comportamento diante da escrita.

\section{Referências}

ADAM, J.-M. A lingüistica textual: introdução à análise textual dos discursos. Tradução Maria das Graças Soares Rodrigues et al. Revisão científica João Gomes Silva Neto. São Paulo: Cortez, 2008.

ÁLVAREZ, M. Tipos de escrito I: narración y descripción. Madrid: Arco Libros, 2003. 
ANTUNES, I. Lutar com palavras: coesão e coerência. São Paulo:

Parábola, 2005.

BASTOS, L. K. Coesão e coerência em narrativas escolares. São Paulo: Martins Fontes, 2001.

BECHARA, S. F.; MOURE, W. G. ¡Ojo con los falsos amigos! 2. ed. São Paulo: Moderna, 2002.

CABRAL, M. Avaliação e escrita: um processo integrado.

In: FONSECA, F. I. (Org.). Pedagogia da escrita - perspectivas. Porto:

Porto, 1994. p. 107-127.

CAMPS, A. Writing process models: some implications for language instruction. Infancia y Aprendizaje, v. 49, p. 3-19, 1990.

CASSANY, D. Reparar la escritura. Didáctica de la corrección de lo escrito. Barcelona: Graó, 1993.

DIONÍSIO, A. P. A postura interacional do narrador. Trabalhos de Lingüística Aplicada, v. 23, p. 11-29, 1994.

FLOWER, L.; HAYES, J. R. Textos en contextos. 1. Los procesos de lectura y escritura. Buenos Aires, 1981. Disponível em: <http://bit.do/bFFN8>. Acesso em: 3 mar. 2014.

GERALDI, J. W. Concepções de linguagem e ensino de português. In: GERALDI, J. W. (Org.). O texto na sala de aula. São Paulo: Ática, 2001. p. 39-46.

IZQUIERDO, I. Memória. Porto Alegre: Artmed, 2002.

JESUS, C. A. de. Reescrevendo o texto: a higienização da escrita, In: GERALDI, J. W.; CITELLI, B. (Coords.). Aprender e ensinar com textos de alunos. 3. ed. São Paulo: Cortez, 2000. p. 99-117.

KOCH, I. V.; ELIAS, V. M. Ler e escrever. Estratégias de produção textual. São Paulo: Contexto, 2009. 
LABOV, W. The transformation of experience in narrative syntax. In:

LABOV, W. Language in the inner city. Studies in the black English vernacular. Philadelphia: University of Pennsylvania Press, 1972. p. 354-397.

LABOV, W.; WALETZKY, J. Narrative analysis: Oral versions of personal experience. In: HELMS, J. (Ed.). Essays on the verbal and visual arts. Seattle: University of Washington Press, 1967. p. 12-44.

MARCUSCHI, L. A. Da fala para a escrita: atividades de retextualização. 8. ed. São Paulo: Cortez, 2007.

MARCUSCHI, L. A. Produção textual, análise de gêneros e compreensão. São Paulo: Parábola, 2008.

MARCUSCHI, L. A. Gêneros textuais: definição e funcionalidade. In: DIONÍSIO, A. P.; MACHADO, A. R.; BEZERRA, M. A. Gêneros textuais e ensino. São Paulo: Parábola, 2010. p. 19-38.

MILANI, E. M. Gramática do espanhol para brasileiros. São Paulo: Saraiva, 2000.

REYES, G. Cómo escribir bien en español. 5. ed. Madrid: Cuadernos de Lengua española; Arco Libros, 2006.

ROHMAN, D. G. Pre-writing. The stage of discovery in the writing process. College Composition and Communication, v. 16, n. 2, p. 106-112, May 1965.

RUIZ, E. M. Como se corrige redação na escola. Campinas: Mercado das Letras, 2001.

SCHIFFRIN, D. Tense variation in narrative. Language, v. 57, n. 1, p. 45-62, 1981.

SERAFÍNI, M. T. Como escrever textos. Tradução Maria Augusta Bastos Matos. 11. ed. São Paulo: Globo, 2001.

SILVEIRA, M. I. M. As narrativas: sua importância na nossa vida e na escola. In: CAVALCANTE, M. A. da S.; FUMES, N. de L. F. (Orgs.). Educação e linguagem. Saberes e práticas. Maceió: EDUFAL, 2006. p. 75-89. 
VAN DIJK, T. A. La ciencia del texto. Barcelona: Paidós, 1983.

VAN DIJK, T. A. Cognição, discurso e interação. Tradução Ingedore Villaça Koch. São Paulo: Contexto, 1996.

Recebido em: 11/05/2015

Aceito: 17/11/2015 